\title{
Triple-orifice repair in severe barlow disease with multiple-jet regurgitation: report of mid-term experience
}

\author{
C Fucci, G DeCicco, L Latini, G DiMatteo, G Coletti \\ From 23rd World Congress of the World Society of Cardio-Thoracic Surgeons \\ Split, Croatia. 12-15 September 2013
}

\section{Background}

Barlow disease represents a surgical challenge for mitral valve repair (MR) in the presence of mitral insufficiency (MI) with multiple regurgitant jets. We hereby present our mid-term experience using a midified edge-to-edge technique to address this peculiar MI.

\section{Methods}

From March 2003 till December 2012, 28 patients (mean age $53.8+/-6$ years, 16 males) affected by severe Barlow disease with multiple jets were submitted to MR. Preoperative transesophageal echo (TEE) in all the cases showed at least 2 regurgitant jets, involving one or both leaflets in more than one segment. In all the patients, a triple-orifice valve (TOV) repair with annuloplasty was performed. Intraoperative TEE and postoperative transthoracic echocardiography (TT) were carried out to evaluate results of the TOV repair.

\section{Results}

There was no in-hospital death and one late death (noncardia related). At intraoperative TEE, the three orifices showed a mean total valve area of $2.98+/-0.3 \mathrm{~cm} 2$ (range: 2.5-3-3) with no residual regurgitation (2 cases of trivial) and no sign of valve stenosis (mean transvalvular gradient 4.5+/-1-3 mmHg.). At follow-up (mean: $68.9+/-12$ months), TEE showed favourable MR and no recurrence of significant MI ( 6 cases of trivial and 1 of mild MI). Stress TEE was performed in 5 cases showing persistent effective velve function (2 cases of trivial MI at peak exercise). All the patients showed significant NYHA functional class improvement.

\footnotetext{
* Correspondence: carlofucci@libero.it

Cardiac Surgery Department, Civic Hospital, Brescia, Italy
}

\section{Conclusions}

This report indicates that the TOV technique is effective in correcting complex Barlow mitral valves with multiple jets. Further studies are required to confirm longterm applicability and durability in more numerous cases.

Published: 11 September 2013

doi:10.1186/1749-8090-8-S1-0275

Cite this article as: Fucci et al.: Triple-orifice repair in severe barlow disease with multiple-jet regurgitation: report of mid-term experience. Journal of Cardiothoracic Surgery 2013 8(Suppl 1):0275.
Submit your next manuscript to BioMed Central and take full advantage of:

- Convenient online submission

- Thorough peer review

- No space constraints or color figure charges

- Immediate publication on acceptance

- Inclusion in PubMed, CAS, Scopus and Google Scholar

- Research which is freely available for redistribution
C Biomed Central

\section{Biomed Central}

(c) 2013 Fucci et al; licensee BioMed Central Ltd. This is an Open Access article distributed under the terms of the Creative Commons Attribution License (http://creativecommons.org/licenses/by/2.0), which permits unrestricted use, distribution, and reproduction in any medium, provided the original work is properly cited. 